\title{
CONTEÚDO DE GORDURA SÓlIDA DA GORDURA ABDOMINAL DE FRANGO, DE SUAS ESTEARINAS E DE SUAS MISTURAS BINÁRIAS COM TOUCINHO ${ }^{1}$
}

\author{
Ming Chih CHIU² e Luiz Antonio GIOIELLI ${ }^{2 * *}$
}

\begin{abstract}
RESUMO
O conteúdo de gordura sólida é um parâmetro utilizado para definir as aplicações mais indicadas de uma gordura, ou de misturas de gorduras, em um determinado produto. Este parâmetro é normalmente determinado por ressonância magnética nuclear e se relaciona com a consistência da gordura. O fracionamento a seco de óleos e gorduras consiste na separação dos triacilgliceróis de acordo com seu ponto de fusão através da cristalização. Além da mistura, o fracionamento é o método mais econômico no processamento de lipídios, pois se trata de um processo puramente físico, comparado às modificações químicas tais como a hidrogenação e a interesterificação, que alteram os triacilgliceróis. As interações que ocorrem entre os triacilgliceróis nas misturas promovem alterações nas propriedades físicas das gorduras. O objetivo do trabalho foi analisar as interações que ocorrem em misturas binárias de duas gorduras animais (gordura abdominal de frango e toucinho) quanto a sua propriedade de conteúdo de gordura sólida a diferentes temperaturas. Foi aplicado um modelo de regressão múltipla do tipo quadrático. Os resultados demonstraram que ocorreram os efeitos eutético e de formação de compostos entre as misturas.
\end{abstract}

Palavras-chave: conteúdo de gordura sólida; mistura; gordura abdominal de frango; estearina; toucinho.

\section{SUMMARY}

SOLID FAT CONTENT OF ABDOMINAL CHICKEN FAT, ITS STEARINS AND ITS BINARY MIXTURES WITH BACON. Solid fat content is a parameter used to define the most appropriate applications of a fat or fat blends in a specific product. This parameter is normally measured by the nuclear magnetic resonance method, and it is related to the consistency of fat. Dry fractionation of oils and fats is the separation of high melting from low melting triacylglycerols by crystallization from the melt. Apart from blending, this is the most economical process in oil and fat processing. It is a purely physical process compared to other chemical modification processes, such as hydrogenation and interesterification, which modify the triacylglycerols. The interactions that occur among the triacylglycerols in the mixtures change the physical properties of the fat. The objective of the paper was to analyze the interactions that occur in binary mixtures of two animal fats (abdominal chicken fat and bacon fat), regarding their solid fat content at different temperatures. A mathematical model of multiple regression of the quadratic type was applied. The results showed that an eutectic effect and compound formation can be observed.

Keywords: solid fat content; mixture; abdominal chicken fat; stearin; bacon.

\section{1 - INTRODUÇÃO}

O conteúdo de gordura sólida indica o percentual de gordura que se encontra no estado sólido a uma determinada temperatura. A espectrometria de ressonância magnética nuclear é atualmente o método de escolha na determinação desta propriedade. O método se baseia nas diferenças entre os decaimentos de energia das fases sólida e líquida de uma gordura quando exposta a um intenso pulso de rádio-freqüência. A medida da intensidade de energia em vários pontos do decaimento permite a determinação da quantidade de prótons presentes nas fases sólida e líquida. O método de ressonância nuclear magnética é mais rápido, mais preciso e fornece resultados mais próximos ao teor absoluto de gordura sólida em relação a técnicas como dilatometria e análise térmica diferencial $[7,17,35]$. Nestas últimas a determinação é indireta e, portanto, os resultados são expressos como índice de gordura sólida. Há relação direta entre o conteúdo de gordura sólida e a consistência da gordura, mas não necessariamente linear [5, 22, 24, 27, 28, 39].

As interações que ocorrem entre os triacilgliceróis nas misturas de gorduras são os principais fatores que influenciam os comportamentos de fusão e cristaliza- ção. GIOIELLI [19] e SATO, UENO, YANO [32] descreveram três tipos de sistemas binários que podem ser observados: soluções sólidas contínuas, sistema eutético e sistema monotético.

O Brasil é o segundo maior produtor e exportador mundial de carne de frango. A produção total brasileira de carne de frango atingiu cerca de 5,5 milhões de toneladas em 1999, o que equivale a 3,1 bilhões de aves [3, 4]. A gordura abdominal corresponde a aproximadamente 2 a $2,5 \%$ do peso total do frango abatido [8, 18]. Esta gordura pode ser aproveitada como um ingrediente na fabricação de rações e embutidos, pois apresenta altos teores de ácido oléico, palmítico e linoléico. Contudo, os pequenos abatedouros a descartam, juntamente com as vísceras, penas e sangue contribuindo, desta forma, com o aumento dos dejetos lançados na natureza.

VIAU \& GANDEMER [37] descreveram a composição em ácidos graxos, a estrutura dos triacilgliceróis, os conteúdos de colesterol e tocoferol e a proporção de gordura sólida entre $0^{\circ} \mathrm{e} 40^{\circ} \mathrm{C}$ de várias gorduras de aves, como frango, pato e ganso. As proporções relativas de ácidos graxos saturados, monoinsaturados e polinsaturados variaram, respectivamente, de $29 \%$ a $35 \%$, de $47 \%$ a $57 \%$ e de $10 \%$ a $24 \%$, de acordo com a gordura analisa-

\footnotetext{
${ }^{1}$ Recebido para publicação em 31/05/01. Aceito para publicação em 04/01/02.

${ }^{2}$ Universidade de São Paulo. Faculdade de Ciências Farmacêuticas. Departamento de Tecnologia Bioquímico-Farmacêutica. Cx Postal 66083, CEP 05315-970. São Paulo-SP. lagio@usp.br.

* A quem a correspondência deve ser enviada.
} 
da. A quantidade de tocoferol encontrada foi muito baixa $(<6 \mathrm{ppm})$. Os conteúdos de colesterol variaram de $40 \mathrm{mg}$ a $70 \mathrm{mg}$ por $100 \mathrm{~g}$ de gordura. Os principais triacilgliceróis foram $\mathrm{PO}_{2}, \mathrm{POL}, \mathrm{LO}_{2}, \mathrm{O}_{3}$ e $\mathrm{P}_{2} \mathrm{O}$, onde $\mathrm{P}=$ ácido palmítico, $\mathrm{O}$ = ácido oléico e $\mathrm{L}$ = ácido linoléico.

Os ácidos graxos saturados influenciam fortemente o conteúdo de gordura sólida dos lipídios, devido ao seu elevado ponto de fusão, que varia de $63^{\circ} \mathrm{C}$ a $70^{\circ} \mathrm{C}$ [26]. As gorduras são invariavelmente misturas de diferentes triacilgliceróis e cada um destes apresenta seu próprio ponto de fusão. Portanto, as gorduras não apresentam um ponto de fusão específico, mas sim uma faixa de fusão [15].

O objetivo do trabalho foi analisar as interações que ocorrem em misturas binárias de gordura abdominal de frango e suas estearinas com gordura suína (toucinho), em relação ao conteúdo de gordura sólida.

\section{2 - MATERIAL E MÉTODOS}

\section{1 - Material}

Foram utilizadas amostras brutas de gordura abdominal de frango de diferentes raças comerciais, gentilmente fornecidas por microempresas, e gordura de toucinho obtida da fusão da gordura retirada do toucinho.

\section{2 - Métodos}

\subsection{1 - Fracionamento}

Foi realizado o fracionamento da gordura de frango por cristalização a seco às temperaturas de $17,5^{\circ} \mathrm{C} \mathrm{e} 20^{\circ} \mathrm{C}$, obedecendo-se as seguintes etapas:

- As amostras de gorduras foram inicialmente fundidas em forno de microondas até a temperatura de $70^{\circ} \mathrm{C}$, para assegurar a completa fusão dos cristais. Posteriormente, foram colocadas em estufa à temperatura de fracionamento.

- Após 24 horas a gordura parcialmente cristalizada foi filtrada sob pressão reduzida para separação das frações líquida (oleína) e sólida (estearina).

\subsection{2 - Misturas}

Para estudar as interações que ocorrem em misturas binárias, foi utilizado um planejamento de seis experimentos, nas seguintes proporções: 100/0, 80/20, $60 / 40,40 / 60,20 / 80,0 / 100$. Foram realizadas misturas da gordura de toucinho com gordura de frango, com estearina obtida a $17,5^{\circ} \mathrm{C}$ de gordura de frango e com estearina obtida a $20^{\circ} \mathrm{C}$ de gordura de frango.

As amostras foram preparadas por mistura nas proporções mencionadas, após fusão completa à temperatura de $60-70^{\circ} \mathrm{C}$ e novamente solidificadas, sendo armazenadas sob resfriamento.

Para a resposta analítica foi aplicado um modelo matemático de regressão múltipla do tipo quadrático por tratar-se de um experimento com misturas de dois com- ponentes [23]. Este modelo matemático está representado pela seguinte equação:

$\mathrm{y}=\beta_{1} \mathrm{x}_{1}+\beta_{2} \mathrm{x}_{2}+\beta_{12} \mathrm{x}_{1} \mathrm{x}_{2}$

Onde:

$\mathrm{y}$ = conteúdo de gordura sólida;

$\beta=$ coeficientes gerados por regressão múltipla;

$\mathbf{x}=$ proporção de cada componente.

Foi utilizado o aplicativo Statgraphics versão 2.6, que permitiu a obtenção dos coeficientes para o modelo, além de apresentar seus níveis de significância, coeficientes de determinação e análise de variância.

\subsection{3 - Conteúdo de gordura sólida}

A determinação foi realizada segundo a AOCS, método Cd 16b-93 [1]. Foi utilizado o método direto, sendo que as leituras das amostras foram feitas em série nas temperaturas de $10,15,20,25,30$ e $35^{\circ} \mathrm{C}$. O equipamento utilizado foi o Espectrômetro de Ressonância Magnética Nuclear Maran Ultra Benchtop, de 20MHz.

\subsection{4 - Composição em ácidos graxos}

A análise da composição em ácidos graxos foi realizada em cromatógrafo a gás Varian GC, modelo 3400 CX, equipado com detector de ionização de chama e integrador eletrônico, modelo CG-300. Foi utilizada coluna capilar de sílica fundida VA-WAX (Varian), com 30m de comprimento $\times 0,25 \mathrm{~mm}$ de diâmetro interno e fase estacionária: polietilenoglicol $(0,25 \mu \mathrm{m}$ de espessura). As condições foram: injeção split, razão de 50:1; temperatura da coluna: $150^{\circ} \mathrm{C}$ por 11 minutos, programada até $210^{\circ} \mathrm{C}$ numa razão de $3^{\circ} \mathrm{C}$ por minuto; gás de arraste: hélio, numa vazão de $1,5 \mathrm{~mL}$ por minuto; gás "make-up": hélio a $30 \mathrm{~mL}$ por minuto; temperatura do injetor: $250^{\circ} \mathrm{C}$; temperatura do detector: $280^{\circ} \mathrm{C}$. A composição qualitativa foi determinada por comparação dos tempos de retenção dos picos com os dos respectivos padrões de ácidos graxos. A composição quantitativa foi realizada por normalização de área, sendo expressa como porcentagem em massa.

O índice de iodo foi calculado a partir da composição em ácidos graxos segundos as normas da AOCS, método Cd 1c-85 [2]. O resultado foi expresso em g de iodo/ $100 \mathrm{~g}$ de gordura. O índice de saponificação foi calculado a partir da composição em ácidos graxos, em função da definição do índice, que corresponde ao número de $\mathrm{mg}$ de hidróxido de potássio necessárias para saponificar um grama de óleo ou gordura. A equação utilizada foi a seguinte [33]:

Índice de saponificação: 56000/(MM média + 12,67)

Onde: $\mathrm{MM}=$ massa molar média dos ácidos graxos. 


\section{3 - RESULTADOS E DISCUSSÃO}

Os resultados apresentados na Tabela 1 representam os rendimentos obtidos das frações sólidas e líquidas da gordura de frango às temperaturas de $17,5^{\circ} \mathrm{C} \mathrm{e} 20^{\circ} \mathrm{C}$.

TABELA 1. Rendimento das oleínas e estearinas obtidas pelo fracionamento da gordura de frango.

\begin{tabular}{lc}
\hline \multicolumn{1}{c}{ Amostras } & Rendimentos $(\%)$ \\
\hline Estearina a $17,5^{\circ} \mathrm{C}$ & 15,7 \\
Oleína a $17,5{ }^{\circ} \mathrm{C}$ & 84,3 \\
Estearina a $20^{\circ} \mathrm{C}$ & 9,6 \\
Oleína a $20{ }^{\circ} \mathrm{C}$ & 90,4 \\
\hline
\end{tabular}

Os resultados encontrados para a composição em ácidos graxos da gordura de frango e para os índices de iodo e saponificação (Tabela 2) estiveram compativeis com a literatura consultada. As pequenas diferenças provavelmente são devidas a fatores intrínsecos às aves, tais como: idade, sexo, raça, tipo de alimentação, clima e o tipo de tecido adiposo analisado [6, 9, 10, 11, 30, 34, 37, 38]. Os resultados obtidos para os mesmos parâmetros acima mencionados, para a gordura de toucinho, estiveram de acordo com a literatura pesquisada [12, 21, 29, 31, 34, 40]. A composição em ácidos graxos da gordura de toucinho varia de acordo com a alimentação, origem, espécie, e localização da gordura presente no suíno [21]. Esta gordura contém quantidades consideráveis dos ácidos palmítico, esteárico, oléico e linoléico, e, menores quantidades dos ácidos mirístico, palmitoléico, linolênico e araquidônico. Sua composição em triacilgliceróis compreende $7 \%$ de trissaturados e $30 \%$ de dissaturados. Quando comparada ao sebo bovino, a gordura de toucinho apresenta maior quantidade de triacilgliceróis com duas duplas ligações e de triacilgliceróis com três duplas ligações. Animais não-ruminantes como os suínos incorporam rapidamente os ácidos graxos insaturados da dieta em seus depósitos tissulares de gordura [29]. Devido a este comportamento metabólico, a gordura de toucinho apresenta elevados índices de ácidos graxos insaturados como o ácido oléico $(47,1 \%)$.

TABELA 2. Composição em ácidos graxos e índices de iodo e de saponificação da gordura de frango e suas frações, e da gordura de toucinho.

\begin{tabular}{ccccccc}
\hline $\begin{array}{c}\text { Ácidos } \\
\text { Graxos } \\
(\%)\end{array}$ & \multicolumn{7}{c}{ Amostras } \\
\cline { 2 - 7 } & $\begin{array}{c}\text { Estearina a } \\
17,5^{\circ} \mathrm{C}\end{array}$ & $\begin{array}{c}\text { Estearina } \\
\mathrm{a} 20^{\circ} \mathrm{C}\end{array}$ & $\begin{array}{c}\text { Oleína a } \\
17,5^{\circ} \mathrm{C}\end{array}$ & $\begin{array}{c}\text { Oleína a } \\
20^{\circ} \mathrm{C}\end{array}$ & $\begin{array}{c}\text { Gordura } \\
\text { de Frango }\end{array}$ & $\begin{array}{c}\text { Gordura de } \\
\text { Toucinho }\end{array}$ \\
\hline $14: 0$ & 0,8 & 0,7 & 0,4 & 0,7 & 0,9 & 1,4 \\
$16: 0$ & 32,9 & 33,9 & 23,5 & 24,1 & 26,4 & 23,5 \\
$16: 1$ & 6,3 & 6,0 & 8,0 & 7,9 & 7,3 & 2,3 \\
$18: 0$ & 8,5 & 9,3 & 5,0 & 5,3 & 5,5 & 10,8 \\
$18: 1$ & 35,2 & 34,3 & 42,4 & 42,0 & 37,5 & 47,1 \\
$18: 2$ & 15,3 & 14,7 & 19,5 & 18,8 & 21,2 & 14,3 \\
$18: 3$ & 1,0 & 1,0 & 1,2 & 1,1 & 1,2 & 0,6 \\
I.I.* & 65,3 & 63,3 & 80,9 & 79,2 & 79,1 & 69,1 \\
I.S.* & 197,7 & 197,8 & 196,3 & 196,5 & 196,9 & 195,4 \\
\hline
\end{tabular}

*I.I. = Índice de iodo (g iodo $/ 100 \mathrm{~g}$ )

*I.S. = Îndice de saponificação (mg KOH/g)
O comportamento de fusão das gorduras animais é complexo, uma vez que consiste em diferentes tipos de triacilgliceróis. Baseando-se na classificação dos triacilgliceróis, quando são distinguidos por seus ácidos graxos saturados, monoinsaturados ou polinsaturados, há 14 tipos de acilgliceróis presentes no toucinho, em concentração igual ou acima de 1\%. No toucinho, o ácido palmítico está preferencialmente esterificado na posição sn-2, o ácido esteárico na posição sn-1 e os ácidos oléico e linoléico na posição sn-3. Já no sebo bovino o ácido oléico ocupa principalmente a posição sn-2. Com isso, a cristalização do toucinho ocorre na forma $\beta$, enquanto que o sebo bovino cristaliza na forma $\beta^{\prime}$ [17].

CORREA-CABRERA et al. [13] relataram que para algumas matérias-primas, em especial a gordura de frango, torna-se conveniente modificar o conteúdo em frações de baixos pontos de fusão, de modo a melhorar o seu comportamento térmico. Assim, o fracionamento térmico controlado ou a hidrogenação parcial podem ser utilizados a fim de obter frações mais duras que permitam manter as características organolépticas sem influenciar negativamente a estabilidade frente à variação de temperatura.

$\mathrm{O}$ índice de iodo da gordura de frango esteve próximo ao citado por BIONDIC [6], que relatou valor de 78,5. Entretanto, o índice de saponificação relatado foi de 184,7 , enquanto que neste estudo obteve-se 196,9. As diferenças entre os indices de iodo das estearinas em relação às oleínas foram de 15,6 e 15,9 unidades, às temperaturas de fracionamento de 17,5 e $20^{\circ} \mathrm{C}$, respectivamente. O teor de ácido oléico nas oleínas foi maior que para a gordura de frango, embora o teor de ácido linoléico tenha sido menor. Isto pode ser devido ao fato que o ácido linoléico encontra-se presente nos triacilgliceróis ligado principalmente a ácidos graxos saturados. Com relação ao índice de saponificação pode-se observar que a diferença entre a gordura de frango e suas frações foi mínima, porque o peso molecular médio dos ácidos graxos nas gorduras é praticamente o mesmo.

Os resultados do conteúdo de gordura sólida das amostras em função da temperatura são apresentados nas Figuras 1 a 3, representando a média de duas determinações. Os resultados das curvas de sólidos demonstraram que as misturas binárias apresentam perfis distintos, possibilitando obter misturas que cobrem faixas variadas do conteúdo de gordura sólida em função da temperatura. O conteúdo de gordura sólida da mistura binária de estearina a $17,5^{\circ} \mathrm{C}$ com gordura de toucinho nas proporções de 100/0 e 80/20 nas temperaturas estudadas pode permitir seu uso em "shortenings" destinados à fabricação de produtos de pastelaria e na proporção de $60 / 40$ pode ser utilizada em "shortenings" destinados à panificação e confeitaria. Para a mistura binária de estearina a $20^{\circ} \mathrm{C}$ este mesmo parâmetro torna esta fração adequada à fabricação de margarinas para aplicação em massas folhadas, e, nas proporções de 60/40 e 40/60 são adequadas para a fabricação de "shortenings" destinados à confecção de produtos de panificação e "shortenings" para todos os tipos de produtos, respectivamente [34]. Segundo CHIU \& GIOIELLI [10], a gordura de frango apresenta-se líquida ou semi-líquida à temperatura 
ambiente, podendo ser utilizada para diversos fins culinários: condimentos, bolos, frituras, também podendo ser utilizada para melhorar a consistência de cremes cosméticos. No trabalho com massas, seu comportamento é superior ao óleo de algodão e à gordura suína. VIAU \& GANDEMER [37] verificaram que a baixa quantidade de triacilgliceróis saturados $(<3 \%$ ) causa o pequeno teor de gordura sólida à temperatura ambiente $\left(3 \%-10 \%\right.$ a $\left.20^{\circ} \mathrm{C}\right)$.

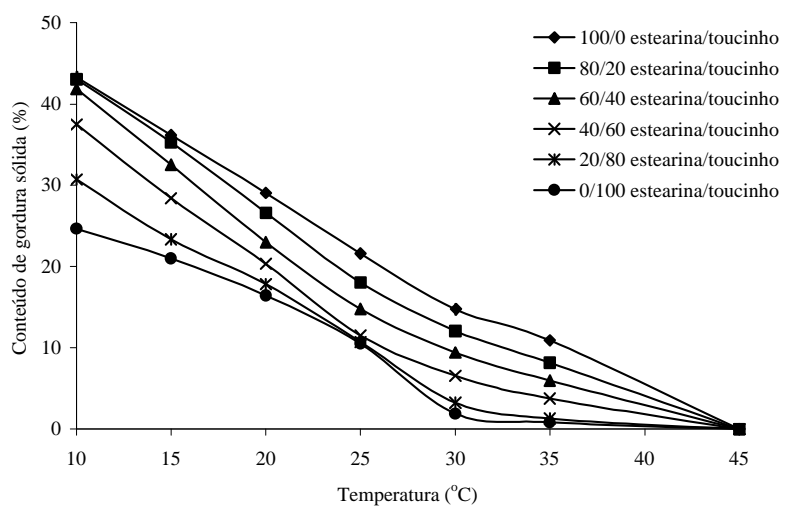

FIGURA 1. Conteúdo de gordura sólida em função da temperatura para misturas de estearina a $17,5^{\circ} \mathrm{C}$ de gordura de frango com gordura de toucinho.

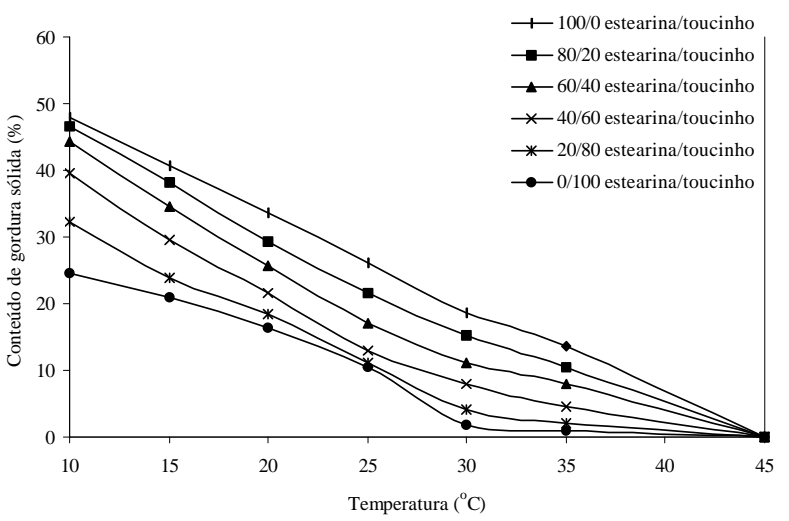

FIGURA 2. Conteúdo de gordura sólida em função da temperatura para misturas de estearina a $20^{\circ} \mathrm{C}$ de gordura de frango com gordura de toucinho.

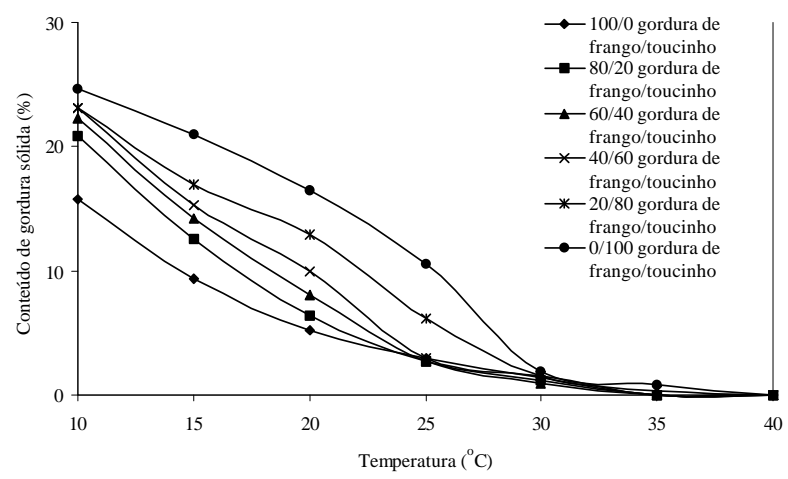

FIGURA 3. Conteúdo de gordura sólida em função da temperatura para misturas de gordura de frango com gordura de toucinho.
GROMPONE et al. [20] afirmaram que a gordura de frango, sendo rica nos ácidos palmítico e palmitoléico, favorece sua possibilidade de emprego na fabricação de margarinas. CHIU \& GIOIELLI [9], relataram que as misturas de gordura abdominal de frango com gordura de toucinho à temperatura de $10^{\circ} \mathrm{C}$ apresentaram faixa adequada de consistência, evidenciando que são adequadas para a elaboração de margarinas.

A Tabela 3 apresenta os coeficientes calculados por regressão múltipla a partir dos resultados experimentais do conteúdo de gordura sólida. Os coeficientes não significativos $(p<0,05)$ foram eliminados. Os resultados demonstraram que a gordura de toucinho não apresentou efeito sobre o conteúdo de gordura sólida a $35^{\circ} \mathrm{C}$, quando misturado às estearinas. Os coeficientes relativos às interações significativas entre as estearinas e a gordura de toucinho e também para as misturas binárias de gordura de frango com gordura de toucinho foram negativos de 20 a $35^{\circ} \mathrm{C}$, demonstrando um efeito antagônico para a propriedade de conteúdo de gordura sólida, característico das interações eutéticas entre triacilgliceróis ou entre gorduras. Este efeito ocorre em função da pequena intersolubilidade no estado sólido dos triacilgliceróis e pode ser caracterizado pela depressão nas linhas de iso-sólidos, quando a proporção de gordura de toucinho está ao redor de $60 \%$, como no caso da mistura de gordura de frango com gordura de toucinho (Figura 4). Para as misturas binárias das estearinas com gordura de toucinho o eutético varia na faixa de 60 a $80 \%$ de gordura de toucinho (Figuras 5 e 6). Por outro lado, à temperatura de $10^{\circ} \mathrm{C}$, os coeficientes relativos às interações foram positivos, caracterizando a chamada formação de compostos [7, 9, 12, 36]. Neste caso, a interação resulta em um empacotamento molecular favorável das cadeias de ácidos graxos, aumentando o conteúdo de gordura sólida, em relação às gorduras originais. Na Figura 4 evidencia-se este tipo de interação, apresentada pelas curvas iso-sólidos, ocorrendo nas misturas entre as gorduras de frango e de toucinho na proporção de $80 / 20$, em temperaturas mais baixas. A formação de compostos ocorre em sistemas binários do tipo PPO/POP, StPO/POP, EPE/PEE e POP/OPO, onde $\mathrm{P}=$ palmítico, $\mathrm{O}=$ oléico, $\mathrm{St}=$ esteárico e $\mathrm{E}=$ elaídico. Essa interação ocorre em misturas de óleo de palma (com cerca de $30 \%$ de POP) e banha (com cerca de 50\% de OPO). A mistura 1:1 de óleo de palma e banha contém $28 \%$ de sólidos a $22^{\circ} \mathrm{C}$, enquanto os componentes apresentam 20 e $22 \%$, respectivamente. Esse efeito é responsável pela arenosidade em margarinas produzidas com estas misturas. Outro exemplo é verificado na mistura de uma fração de óleo de palma interesterificada (com cerca de 66\% de PPO) com uma fração intermediária de óleo de palma (rica em POP) [9, 14]. VIAU \& GANDEMER [37] afirmam que a gordura de frango apresenta em sua composição principalmente triacilgliceróis do tipo: $\mathrm{PO}_{2}, \mathrm{POL}, \mathrm{LO}_{2}, \mathrm{O}_{3}$ e $\mathrm{P}_{2} \mathrm{O}$, onde $\mathrm{P}=$ ácido palmítico, $\mathrm{O}=$ ácido oléico, $\mathrm{L}=$ ácido linoléico. $\mathrm{O}$ triacilglicerol do tipo $\mathrm{P}_{2} \mathrm{O}$ pode, portanto, ter levado à formação de compostos nas misturas entre gordura abdominal de frango com a gordura de toucinho. Para que a formação de com- 
postos ocorra, são necessárias as seguintes condições: a) mistura de trialcilgliceróis mono-insaturados simétricos e assimétricos; b) trialcilgliceróis simétricos contendo somente um tipo de ácido graxo saturado; c) trialcilgliceróis assimétricos contendo dois ácidos graxos saturados diferentes, desde que o ácido comum a ambos acilgliceróis esteja na posição sn-2. Quando estas condições ocorrem, as cadeias de ácidos graxos empacotam formando três ácidos idênticos lado a lado. De acordo com D'AGOSTINI, GIOIELLI, FERRAZ [14] as interações que ocorrem entre os triacilgliceróis nas misturas binárias e ternárias de óleos e gorduras são os principais fatores que influenciam o comportamento de gorduras quanto a sua fusão e cristalização.

TABELA 3. Coeficientes calculados por regressão múltipla, para o conteúdo de gordura sólida, a partir dos resultados experimentais das misturas de gordura de frango com gordura de toucinho (A), estearina a $17,5^{\circ} \mathrm{C}$ de gordura de frango com gordura de toucinho (B) e estearina a $20^{\circ} \mathrm{C}$ de gordura de frango com gordura de toucinho (C).

\begin{tabular}{ccccc}
\hline Resultado & \multicolumn{5}{c}{ Coeficientes } \\
\cline { 2 - 5 } $\mathrm{A}$ & $\beta_{1}$ & $\beta_{2}$ & $\beta_{12}$ & $\mathrm{R}^{2}$ \\
\hline $\mathrm{CGS}(\%) \mathrm{a}$ & & & & \\
$10^{\circ} \mathrm{C}$ & 16,50 & 23,96 & 10,54 & 0,999 \\
$15^{\circ} \mathrm{C}$ & 10,00 & 20,34 & 0 & 0,998 \\
$20^{\circ} \mathrm{C}$ & 5,33 & 16,38 & $-7,59$ & 0,999 \\
$25^{\circ} \mathrm{C}$ & 3,33 & 10,26 & $-15,96$ & 0,993 \\
$30^{\circ} \mathrm{C}$ & 1,38 & 1,95 & $-1,81$ & 0,993 \\
$35^{\circ} \mathrm{C}$ & 0 & 0,83 & $-1,72$ & 0,976 \\
$\mathrm{~B}$ & & & & \\
$\mathrm{CGS}^{*}(\%) \mathrm{a}$ & & & & \\
$10^{\circ} \mathrm{C}$ & 43,40 & 24,16 & 22,95 & 0,999 \\
$15^{\circ} \mathrm{C}$ & 36,72 & 20,21 & 0 & 0,999 \\
$20^{\circ} \mathrm{C}$ & 29,36 & 16,23 & $-4,31$ & 0,999 \\
$25^{\circ} \mathrm{C}$ & 21,88 & 10,33 & $-11,86$ & 0,999 \\
$30^{\circ} \mathrm{C}$ & 14,91 & 1,55 & 0 & 0,999 \\
$35^{\circ} \mathrm{C}$ & 10,99 & 0 & $-4,69$ & 0,998 \\
$\mathrm{C}$ & & & & \\
$\mathrm{CGS}^{*}(\%) \mathrm{a}$ & & & & 0,999 \\
$10^{\circ} \mathrm{C}$ & 47,85 & 24,46 & 22,83 & 0,999 \\
$15^{\circ} \mathrm{C}$ & 41,15 & 20,26 & 0 & 0,999 \\
$20^{\circ} \mathrm{C}$ & 33,83 & 16,25 & $-6,21$ & 0,999 \\
$25^{\circ} \mathrm{C}$ & 26,52 & 10,30 & $-14,02$ & 0,999 \\
$30^{\circ} \mathrm{C}$ & 18,96 & 1,66 & 0 & 0,998 \\
$35^{\circ} \mathrm{C}$ & 13,76 & 0 & 0 &
\end{tabular}

*CGS = Conteúdo de gordura sólida

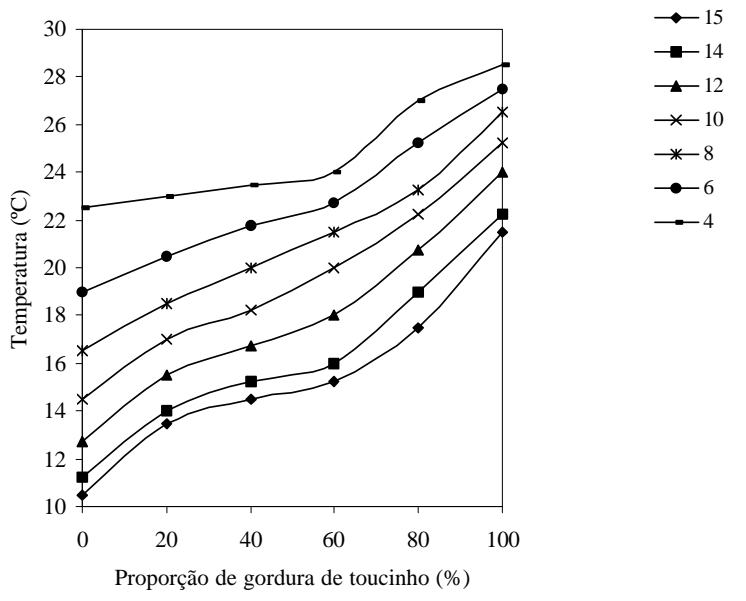

FIGURA 4. Diagrama de curvas de iso-sólidas de misturas de gordura de frango com gordura de toucinho.

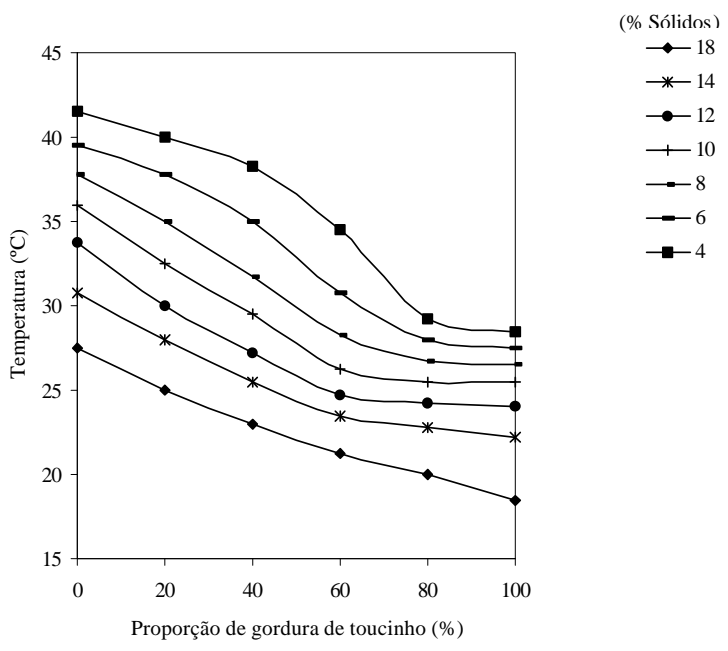

FIGURA 5. Diagrama de curvas de iso-sólidas de misturas de estearina a $17,5^{\circ} \mathrm{C}$ de gordura de frango com gordura de toucinho.

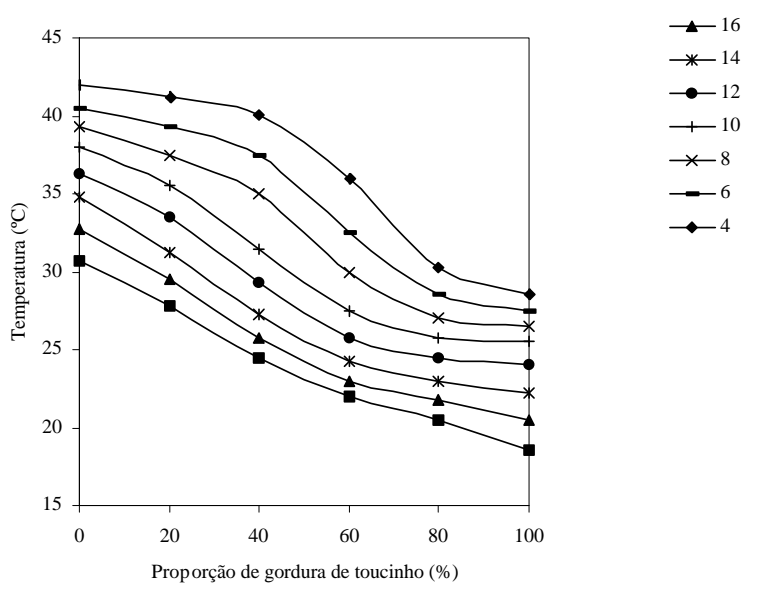

FIGURA 6. Diagrama de curvas de iso-sólidas de misturas de estearina a $20^{\circ} \mathrm{C}$ de gordura de frango com gordura de toucinho.

O nível de significância encontrado para os modelos foi $>97 \%$. Pela Tabela 3 , pode ser observado que a variação das respostas $\left(R^{2}=0,9758\right.$ a 0,9999$)$ pode ser explicada pelas regressões múltiplas, indicando excelente ajuste do modelo aos dados experimentais.

A consistência das amostras foi determinada em trabalho anterior [9]. Como a consistência de gorduras é influenciada pelo conteúdo de gordura sólida do material [9, 16], foi efetuada uma relação entre essas propriedades, por regressão linear simples, apresentada na Tabela 4. A equação da reta correspondente é a seguinte:

$y=a+b \cdot x$

Onde:

$\mathrm{y}=$ conteúdo de gordura sólida (\%) 
$\mathrm{a}=$ coeficiente linear

$\mathrm{b}=$ coeficiente angular

$\mathrm{x}=$ consistência $\left(\mathrm{g} / \mathrm{cm}^{2}\right)$

Os resultados da Tabela 4 demonstraram que houve relação linear significativa a $\mathrm{p}<0,05$. O coeficiente linear da reta representa o conteúdo de gordura sólida das amostras de estearinas e de suas misturas quando a consistência é igual a zero, apresentando valores de 12,262 a 28,747 . Isto mostra que, quando o teor de sólidos na gordura é inferior ao redor de $12 \%$, o material apresenta-se como um líquido viscoso, ao invés de se comportar como uma gordura plástica. Guando a proporção de gordura no estado sólido é maior que $12 \%$, o óleo líquido é imobilizado pela matriz cristalina, tornando a gordura plástica $[10,11,14,25]$. A relação entre índice/conteúdo de gordura sólida e consistência é sempre direta, mas não necessariamente linear $[5,9,10$, $11,14,22,24,27,28,39]$.

TABELA 4. Relação entre consistência e conteúdo de gordura sólida, por regressão linear simples, de misturas de estearina a $17,5^{\circ} \mathrm{C}$ de gordura de frango com gordura de toucinho (A) e de estearina a $20^{\circ} \mathrm{C}$ de gordura de frango com gordura de toucinho (B).

\begin{tabular}{|c|c|c|c|}
\hline \multirow[t]{2}{*}{ Resultado } & \multicolumn{3}{|c|}{ Coeficientes } \\
\hline & $\mathrm{a}$ & b & $\mathrm{R}$ \\
\hline \multicolumn{4}{|l|}{ A } \\
\hline \multicolumn{4}{|l|}{ Proporção } \\
\hline $100 / 0$ & 24,552 & 0,005 & 0,960 \\
\hline $80 / 20$ & 22,364 & 0,007 & 0,940 \\
\hline $60 / 40$ & 19,078 & 0,009 & 0,948 \\
\hline $40 / 60$ & 15,722 & 0,015 & 0,944 \\
\hline $20 / 80$ & 14,402 & 0,021 & 0,926 \\
\hline $0 / 100$ & 12,262 & 0,031 & 0,945 \\
\hline B & & & \\
\hline \multicolumn{4}{|l|}{ Proporção } \\
\hline $100 / 0$ & 28,747 & 0,004 & 0,966 \\
\hline $80 / 20$ & 25,586 & 0,005 & 0,943 \\
\hline $60 / 40$ & 21,139 & 0,007 & 0,953 \\
\hline $40 / 60$ & 16,892 & 0,012 & 0,953 \\
\hline $20 / 80$ & 14,342 & 0,023 & 0,954 \\
\hline $0 / 100$ & 12,262 & 0,031 & 0,945 \\
\hline
\end{tabular}

O rendimento do processo de fracionamento em relação as estearinas foi baixo $\left(15,7 \%\right.$ a $17,5^{\circ} \mathrm{C}$ e $9,6 \%$ a $20^{\circ} \mathrm{C}$ ). O conteúdo de gordura sólida das misturas binárias dependeu de todas as frações utilizadas. Os coeficientes negativos para o conteúdo de gordura sólida demonstraram um efeito antagônico característico de interações eutéticas entre gorduras, tendo ocorrido em todas as misturas, na faixa de 20 a $35^{\circ} \mathrm{C}$. Os coeficientes positivos demonstraram um efeito sinérgico, caracterizando a chamada formação de compostos entre misturas de gorduras, que foi observado em todas as misturas à temperatura de $10^{\circ} \mathrm{C}$.

\section{5 - REFERÊNCIAS BIBLIOGRÁFICAS}

[1] A.O.C.S. - AMERICAN OIL CHEMIST'S SOCIETY - Official methods and recommended practices, I. L., 5rd. Ed., Champaign, 1996.
[2] A.O.C.S. - AMERICAN OIL CHEMIST'S SOCIETY - Official methods and recommended practices, 4. ed., Champaign, 1990.

[3] ASSOCIAÇÃO BRASILEIRA DOS EXPORTADORES DE FRANGO. Estatísticas: produção mensal brasileira de aves, histórico do consumo brasileiro de carne de frango, exportações mensais brasileiras de frango.[On-line] Available:http: \\www.abef.com.br[April 27,2001].

[4] ASSOCIAÇÃO PAULISTA DE AVICULTURA. Estatísticas: frangos, produção nacional. [On-line] Available:http: \\www.apa.com.br[April 27,2001].

[5] BALBO, A.M.T.M., GIOIELLI, L.A. Mixtures of babassu fat with palm oil and its fractions: eutectic interactions. Internacional Meeting on Fats \& Oils Technology - GTZ/ UNICAMP, Campinas, SP, 1991, Proceedings. p.184-188.

[6] BIONDIC, B. Gordura de galinha e frango. Indústria Alimentar, n. 1, p. 25-29, 1976.

[7] BIRKER, P. J.M.W.L., PADLEY, F.B. Physical properties of fats and oils. In: HAMILTON, R.J., BHATI, A., eds. Recent advances in chemistry and technology of fats and oils. London: Elsevier, 1987. p.1-11.

[8] BUCHALlA, L. M. Frango Sertanejo LTDA. Guapiaçu-SP. 1999. [Comunicação Pessoal]

[9] CHIU, M. C., GIOIELLI, L. A. Consistência da gordura abdominal de frango, de suas estearinas e de suas misturas binárias com toucinho. Rev. Bras. Ciênc. Farm., 2001b.(submetido para publicação)

[10] CHIU, M. C., GIOIELLI, L. A. Fraccionamiento de la grasa abdominal de pollo. Grasas y Aceites, 2001a. (submetido para publicação)

[11] CHIU, M. C., GIOIELLI, L. A. Fractionation of abdominal chicken fat. Eur. J. Pharm. Sci., v. 13, supl.1, p. S43, 2001 c.

[12] CHIU, M. C., GIOIELLI, L. A. Propriedades físico-químicas das misturas de gordura abdominal de frango, suas estearinas e gordura de toucinho. Rev. Bras. Ciênc. Farm., v. 36, supl.1, p. 41, 2000.

[13] CORREA-CABRERA, R., CAPOTE, A., RODRÍGUEZ-AYÁN, M. N., GROMPONE, M. A. - Caracterización de grasas para caldos deshidratados. Grasas y Aceites, v. 50,n.1,p.30-36, 1999.

[14] D’AGOSTINI, D., FERRAZ, R.C., GIOIELLI, L.A. Consistência de misturas binárias e ternárias de gorduras de palma, palmiste e triacilgliceróis de cadeia média. Rev. Bras. Ciênc. Farm., v. 36, n. 1, p. 147-155, 2000.

[15] DEMAN, J. M., DEMAN, L., BLACKMAN, B. Melting point determination of fat products. J. Am. Oil Chem. Soc., v. 60, n. 1, p. 91-94, 1983.

[16] DEMAN, J.M., BEERS, A.M. Fat crystal networks: structure and rheological properties. J. Texture Stud., v. 18, n. 4, p. 303-318, 1988.

[17] ENSER, M. Meat lipids. In: Hamilton R. J., ed. Developments in oils and fats. 1. ed. London: Chapman \& Hall, 1995, p. 1-31.

[18] GARANTIA DA QUALIDADE. Perdigão Agroindustrial S.A. Abatedouro de Aves, Unidade Videira, Santa Catarina, 2000. [Comunicação Pessoal]

[19] GIOIELLI, L. A. Misturas de óleos e gorduras na formulação de produtos gordurosos. Revista Óleos \& Grãos, n. 32, p. 24-28, 1996.

[20] GROMPONE, M. A.; GUERRA, J. F.; PAZOS, n. A.; MÉNDEZ, E.; LUCAS, E.; JACHMANIÁN, I.; COLLAZI, P. Fraccionamiento térmico de aceite de pollo. Grasas y Aceites, v. 45, n. 6, p. 390-344, 1994.

[21] GUNSTONE, F.D., HARWOOD, J.L., PADLEY, F.B. The lipid handbook. Cambridge: The University Press, 1986. p.113-129. 
[22] HAIGHTON, A.J. Blending chiling, and tempering of margarines and shortenings. J. Am. Oil Chem. Soc., $v$. 53, n. 6, p. 397-399, 1976.

[23] HARE, L.B. Mixture designs applied to food formulation. Food Technol., v. 28, n. 3, p. 50-62, 1974.

[24] LANNES, S.C.S., GIOIELLI, L.A. Características físico-químicas da manteiga de cacau e sucedâneos comerciais. Ciênc. Tecnol. Aliment., v. 15, n. 1, p. 89-94, 1995.

[25] LARSSON, K. - Lipids: molecular organization, physical functions and technical applications. Dundee: The Oily Press, 1994. p.7-45.

[26] LARSSON, K., QUINN, P. J. Physical properties: structural and physical characteristics. In: Gunstone, F. D., Hartwood, J. L., Padley, F. B. eds. The Lipid Handbook, 2 ed., London: Chapman and Hall, 1994, p. 401-460.

[27] LEFEBVRE, J. Finished product formulation. J. Am. Oil Chem. Soc., v. 60, n. 2, p. 295-300, 1983b.

[28] LEFEBVRE, J. Formulation et gestion de la qualité en margarinerie. Rev. Fr. Corps Gras, v. 30, n. 2, p. 59-65, 1983a.

[29] LOVE, J. A. Animal fats. In: Hui, Y. H., ed. Bailey's industrial oil and fat products. 5. ed. New York: Wiley, 1996. v.1, p. 1-18.

[30] ORTHOEFER, F. T. Vegetable oils. In: Hui, Y. H., ed. Bailey's industrial oil and fat products. 5. ed. New York: Wiley, 1996. v.1, p. 19-44.

[31] ROSSEL, J. B. Classical analysis of oils and fats. In: HAMILTON, R. J., ROSSEL, J. B., eds. Analysis of oils and fats. London: Elsevier Applied Science, 1986. p.1-90.

[32] SATO, K., UENO, S., YANO, J. Molecular interactions and kinetic properties of fats. Prog. Lipid Res., v. 38, p. 91$116,1999$.
[33] SINGHAL, R.S., KULKARNI, P. R. Efffect of puffing on oil characteristics of amaranth (Rajgeera) seeds. J. Am. Oil Chem. Soc., v. 67, n. 12, p. 952-954, 1990.

[34] STAUFFER, C. E. Fats and Oils, St. Paul, Eagan Press, 1996. p. 19-43.

[35] TIMMS, R.E. Phase behaviour of fats and their mixtures of oils. J.Am.Oil Chem. Soc., v. 62, n. 2, p. 241-248, 1985.

[36] TIMMS, R.E. Phase behaviour of fats and their mixtures. Prog. Lipid Res., v. 23, n. 1, p. 1-38, 1984.

[37] VIAU, M., GANDEMER, G. Principales caractéristiques de composition des graisses de volaille. Rev. Fr. Corps Gras., v. 38, n. 5-6, p. 171-177, 1991.

[38] VIZCARRONDO, C.A., DE PADILLA, F.C., MARTIN, E. Fatty acid composition of beef, pork, and poultry fresh cuts, and some of their processed products. Archivos Latinoamericanos de Nutricion, v. 48, n. 4, p. 354358, 1998.

[39] WEISS, T.J. Food oils and their uses. 2. ed. Westport: AVI, 1983a. p.1-33.

[40] WEISS, T.J. Food oils and their uses. 2. ed. Westport: AVI, 1983b. p.35-64.

\section{6 - AGRADECIMENTOS}

À Fundação de Amparo à Pesquisa do Estado de São Paulo - FAPESP, à Fundação Coordenação de Aperfeiçoamento de Pessoal de Nível Superior - CAPES e ao Conselho Nacional de Desenvolvimento Científico e Tecnológico - CNPq, pelo auxílio financeiro e pelas bolsas concedidas aos autores. 